\title{
The New Heteronuclear Complexes of Ti(IV) and Dy(III) in Aqueous Solutions
}

\author{
OLGA P. AJSUVAKOVA ${ }^{1 *}$, SERGEY G. BEZRYADIN ${ }^{1}$, VLADIMIR V. CHEVELA ${ }^{2}$, \\ VALENTINA Y. IVANOVA ${ }^{2}$ and DMITRY V. KUZYAKIN ${ }^{1}$ \\ ${ }^{1}$ Department of Chemistry, Orenburg State Agrarian University, \\ Chelyuskintsev st., 18, Orenburg, 460014, Russia \\ ${ }^{2}$ Department of Inorganic Chemistry, A.M. Butlerov Institute of Chemistry of Kazan \\ (Volga Region) Federal University, Kremlevskaya st., 18, Kazan, 420008, Russia \\ *Corresponding author E-mail: oajsuvakova@gmail.com
}

http://dx.doi.org/10.13005/ojc/300401

(Received: September 16, 2014; Accepted: October 26, 2014)

\begin{abstract}
The aqueous interactions between Ti(IV), Dy(III) and citric $\left(\mathrm{H}_{4} \mathrm{Cit}\right)$, d-tartaric $\left(\mathrm{d}-\mathrm{H}_{4}\right.$ Tart) and racemic tartaric acids ( $\mathrm{dl}-\mathrm{H}_{4}$ Tart) acids were investigated by potentiometric titration and nuclear magnetic relaxation methods. The analysis of experimental data was performed using mathematical models to evaluate the possibility of existence of a wide species' set in the solution and to identify those of which account is sufficient to reproduce the observed pattern. The species of different nuclearity were found, the relaxation efficiency $\left(R_{1}\right)$ and equilibrium constants $\left(K_{\text {pmqr }}\right)$ of heteronuclear complexes were calculated. It is shown that the complexation processes are strongly $\mathrm{pH}$-dependent.
\end{abstract}

Key words: Titanium(IV), dysprosium(III), oxyacid, heteronuclear complexes, aqueous solutions.

\section{INTRODUCTION}

One of the most important applications of titanium is manufacturing of medical implants due to its inertness. However, the citrate-ions increase the solubility of the titanium-containing inert materials translating titanium from the solid phase into solution. The authors ${ }^{1,2}$ propose that titanium (IV) citrate complexes are biologically active. Therefore, due to the increased interest in recent years to the complexes of Ti(IV) with $\alpha$-hydroxyacids, the value of the information on the stoichiometry and stability of heteronuclear complexes of titanium (IV) with paramagnetic ions increases. Although a number of authors have actively studied the processes of complex formation of titanium (IV) with hydroxyacids ${ }^{2-12}$, the analysis of literary sources show that the composition and stability of heteronuclear complexes of titanium (IV) is almost unexplored. At the same time, only single 
indications of $\mathrm{Ti}(\mathrm{IV})$ heteronuclear complexes' structure and stability are present $(13,14)$. Therefore, the primary aim of the current work is the investigation of $\mathrm{Ti}(\mathrm{IV})$ and $\mathrm{Dy}(\mathrm{III})$ heteronuclear complexes' formation in aqueous solutions.

\section{MATERIAL AND METHODS}

The investigation of complexes in the system Ti(IV) - Dy(III) - citric acid and Ti(IV) - Dy(III) - tartaric acid was performed using the methods of nuclear magnetic relaxation and $\mathrm{pH}$-metry in the argon medium. We have investigated the interval of the metal concentrations from 0.0026 to $0.01 \mathrm{~mol} / \mathrm{L}$ at the reagent ratios of $1: 1: 2,1: 1: 4$, and $1: 1: 6$ at $\mathrm{pH}$ 1-10.5. $\mathrm{TiCl}_{4}$ (puriss., Fluka), $\mathrm{DyCl}_{3}$ (trace metals basis, Sigma-Aldrich) and citric acid $\left(\mathrm{H}_{4} \mathrm{Cit}\right)$ (ACS reagent, Sigma-Aldrich) were used. In order to estimate possible stereoeffects, $\mathrm{d}$-tartaric $\left(\mathrm{d}-\mathrm{H}_{4}\right.$ Tart) and racemic tartaric acids (dl- $\mathrm{H}_{4}$ Tart) (ReagentPlus, Aldrich) were used. All working solutions were prepared using double distilled water. Final concentrations of $\mathrm{Ti}(\mathrm{IV})$ and $\mathrm{Dy}(\mathrm{III})$ ions were estimated by complexometric method using xylenol orange as an indicator. In the case of Ti(IV) the titration was performed in the presence of hydrogen peroxide. The concentrations of citric, d-tartaric and racemic (dl)-tartaric acids were assessed using standard $0.1 \mathrm{~mol} / \mathrm{L} \mathrm{NaOH}$ solution.

Potentiometric analysis was performed using Hanna Instruments pH-meter "pH 213" (Hanna Instruments, USA). The temperature of the working solutions was kept constant at $25 \pm 0.1^{\circ} \mathrm{C}$. The time of spin-lattice relaxation was assessed using nuclear magnetic resonance analyzer "Spin Track" (Resonance Systems, Russia). The CPESSP software (Russia) was used for evaluation of structure, stability and calculation of the relaxation efficiency coefficients of the complexes analyzed. The mathematic modeling was performed based on the $\mathrm{pH}$-metric data. In the case of the ligand's excess the primary $\mathrm{pH}$-based model was corrected using the proton magnetic relaxation method.

The reactions of complex formation between $\mathrm{H}^{+}, \mathrm{Ti}^{4+}$, $\mathrm{Dy}^{3+}$, and $\mathrm{H}_{4} \mathrm{Cit}$ in the solutions may be represented in the following formalized equation (Eq. 1):

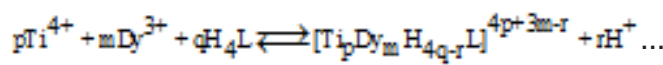

Consequently, the equilibrium constants of heteronuclear complex formation may be calculated as follows (Eq. 2):

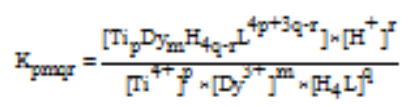

Based on the $\mathrm{pH}$-metric data, the Bjerrum function $\tilde{n}$ was calculated. The Bjerrum function is a function of formation and considers the contribution of every component of the system (Eq. 3):

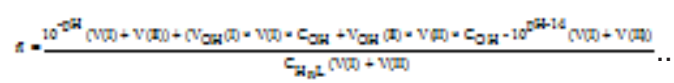

Relaxivity $R_{1}$ (as a formation function) for every point was calculated according to the following equation (Eq. 4):

$$
\mathrm{R}_{1}=\frac{1}{\mathrm{BT}_{1}}
$$

where $R_{1}$ - relaxivity $\left(\mathrm{mol}^{-1} \mathrm{~s}^{-1} \mathrm{~L}, \mathrm{~B}-\right.$ paramagnetic ion concentration (Dy(III)), $\mathrm{mol} / \mathrm{L}, \mathrm{T}_{1}$ time of spin-lattice relaxation, s).

\section{RESULTS AND DISCUSSION}

\section{$\mathrm{Ti}(\mathrm{IV})$ and $\mathrm{Dy}$ (III) citrates}

The comparison of the dependences of Bjerrum function and relaxational efficacy from $\mathrm{pH}$ values in homo- and heteronuclear citratecontaining systems with the curves observed for homonuclear Dy(III) $-\mathrm{H}_{4}$ Cit system shows that heteronuclear Ti(IV) and Dy(III) citrates are formed in the whole analyzed pH range (Fig. 1a, 1b). The calculated stability constants' values of heteronuclear dysprosium (III) and titanium (IV) citrates' formation are presented in the table 1. In the case of equimolar metal : $_{1}$ tal ${ }_{2}$ :ligand ratio the equilibrium is described by the forms of the $1: 1: 2$ composition with different deprotonation degree. Protonated $\left[\mathrm{DyTi}\left(\mathrm{H}_{3} \mathrm{Cit}\right)_{2}\right]^{5+}$ complex is formed already at $\mathrm{pH}=1.5$ (Eq. 5):

$$
\mathrm{Dy}^{3+}+\mathrm{Ti}^{4+}+\mathrm{H}_{4} \mathrm{Cit} \rightleftarrows\left[\mathrm{DyTi}\left(\mathrm{H}_{3} \mathrm{Cit}\right)_{2}\right]^{5+}
$$


The 1:1:2 complex is consecutively deprotonated forming a number of heteronuclear citrates and hydroxycitrates of the 1:1:2 composition $\left(\left[\mathrm{DyTi}\left(\mathrm{H}_{2} \mathrm{Cit}\right)_{2}\right]^{3+} \text {, [DyTi(}\left(\mathrm{H}_{2} \mathrm{Cit}\right)(\mathrm{HCit})\right]^{2+}$, [DyTi(HCit) (Cit) $]^{0},\left[\mathrm{DyTi}(\mathrm{Cit})_{2}\right]$, [DyTi $\left.(\mathrm{OH})(\mathrm{Cit})_{2}\right]^{2-},\left[\mathrm{DyTi}(\mathrm{OH})_{2}\right.$ $\left.(\mathrm{Cit})_{2}\right]^{3-},\left[\mathrm{DyTi}(\mathrm{OH})_{3}(\mathrm{Cit})_{2}\right]^{4-},\left[\mathrm{DyTi}(\mathrm{OH})_{4}(\mathrm{Cit})_{2}\right]^{5-} 8$ $\left.\left[\mathrm{DyTi}(\mathrm{OH})_{5}(\mathrm{Cit})_{2}\right]^{6-}\right)$.

At higher ratios of the reagents the dominating at the strong-acid medium 1:1:3 form is consecutively turned to the complexes of 1:1:4 forms (Eq. 6):

$$
\left[\mathrm{DyTi}\left(\mathrm{H}_{2} \mathrm{Cit}\right)_{3}\right]^{+} \underset{4 \mathrm{H}^{+}}{\stackrel{+\mathrm{H}_{4} \mathrm{Cit}}{\rightleftarrows}}\left[\mathrm{DyTi}\left(\mathrm{H}_{2} \mathrm{Cit}\right)_{2}(\mathrm{HCit})_{2}\right]^{3-}
$$

The monomer $\left[\mathrm{DyTi}\left(\mathrm{H}_{2} \mathrm{Cit}\right){ }_{3}\right]^{+}\left(\mathrm{R}_{1}=568.0\right.$ $\mathrm{mol}^{-1} \mathrm{~s}^{-1} \mathrm{~L}$ ) simultaneously attaches the fourth ligand molecule and is deprotonated forming a number of 1:1:4 forms $\left[\mathrm{DyTi}\left(\mathrm{H}_{2} \mathrm{Cit}\right)_{2}(\mathrm{HCit})_{2}\right]^{3-}$, [DyTi( $\left.(\mathrm{HCit})_{4}\right]^{5-}$, $\left[\mathrm{DyTi}(\mathrm{HCit})_{2}(\mathrm{Cit})_{2}\right]^{]^{-}}\left(\mathrm{R}_{1}=298.1 ; 259.3 ; 277.0 ; 211.2\right.$ $\mathrm{mol}^{-1} \mathrm{~s}^{-1} \mathrm{~L}$, respectively) in the acidic medium. In the alkaline medium at $\mathrm{pH}>7$ the complex $\left[\mathrm{DyTi}(\mathrm{HCit})_{2}(\mathrm{Cit})_{2}\right]^{7-}$ is converted into the deprotonated form $\left[\mathrm{TiDy}(\mathrm{Cit})_{4}\right]^{9-}\left(\mathrm{R}_{1}=211.2 \mathrm{~mol}^{-1} \mathrm{~s}^{-}\right.$ $\left.{ }^{1} \mathrm{~L}\right)$. The verification of the possible formation of the hydroxyforms $\left[\mathrm{TiDyOH}(\mathrm{Cit})_{4}\right]^{10-}$ and $\left[\mathrm{TiDy}(\mathrm{OH})_{2}\right.$ $\left.(\mathrm{Cit})_{4}\right]^{11-}$ in the strong-alkaline medium has provided negative data. In the case of a 3-fold ligand excess the 1:1:6 forms were observed to dominate at the

Table 1: Composition and equilibrium constants log values of Ti(IV) and Dy(III) complexes (Constants determination' error does not exceed 0.3 log units)

\begin{tabular}{|c|c|c|c|c|c|c|c|c|c|c|}
\hline \multicolumn{4}{|c|}{ Stoichiometry matrix } & \multirow{2}{*}{$\begin{array}{l}\log K_{\text {mpqr }} \\
\mathrm{H}_{4} \mathrm{Cit}\end{array}$} & \multicolumn{4}{|c|}{ Stoichiometry matrix } & \multicolumn{2}{|c|}{$\log K_{\text {mpqr }}$} \\
\hline $\begin{array}{l}\text { Dy }^{3+} \\
\text { (m) }\end{array}$ & $\begin{array}{l}\mathrm{Ti}^{4+} \\
(p)\end{array}$ & $\begin{array}{l}\mathrm{H}_{4} \mathrm{~L} \\
\text { (q) }\end{array}$ & $\begin{array}{l}\mathrm{H}^{+} \\
(\mathrm{r})\end{array}$ & & $\begin{array}{l}\mathrm{Dy}^{3+} \\
\text { (m) }\end{array}$ & $\begin{array}{l}\mathrm{Ti}^{4+} \\
\text { (p) }\end{array}$ & $\begin{array}{l}\mathrm{H}_{4} \mathrm{~L} \\
\text { (q) }\end{array}$ & $\begin{array}{l}\mathrm{H}^{+} \\
(\mathrm{r})\end{array}$ & $\begin{array}{l}\text { d- } \\
\mathrm{H}_{4} \text { Tart }\end{array}$ & $\begin{array}{l}\text { dl- } \\
\mathrm{H}_{4} \text { Tart }\end{array}$ \\
\hline 1 & 1 & 2 & 2 & 22.15 & 1 & 1 & 2 & 2 & 6.79 & 6.75 \\
\hline 1 & 1 & 2 & 4 & 19.91 & 1 & 1 & 2 & 4 & 3.80 & 3.73 \\
\hline 1 & 1 & 2 & 5 & 17.54 & 1 & 1 & 2 & 9 & -12.84 & -13.12 \\
\hline 1 & 1 & 2 & 7 & 12.87 & 1 & 1 & 2 & 10 & -19.29 & -19.61 \\
\hline 1 & 1 & 2 & 8 & 10.07 & 1 & 1 & 2 & 11 & -27.77 & -27.97 \\
\hline 1 & 1 & 2 & 9 & 6.53 & 1 & 1 & 2 & 12 & -38.95 & -38.94 \\
\hline 1 & 1 & 2 & 10 & 1.24 & 2 & 2 & 4 & 11 & 2.99 & 2.91 \\
\hline 1 & 1 & 2 & 11 & -5.56 & 2 & 2 & 4 & 14 & -5.72 & -5.95 \\
\hline 1 & 1 & 2 & 12 & -13.68 & 2 & 2 & 4 & 16 & -13.13 & -13.42 \\
\hline 1 & 1 & 2 & 13 & -23.58 & 2 & 2 & 4 & 17 & -18.27 & -18.51 \\
\hline 1 & 1 & 3 & 6 & 17.50 & 2 & 2 & 4 & 18 & -23.98 & -23.74 \\
\hline 1 & 1 & 4 & 10 & 8.87 & 2 & 2 & 4 & 20 & -37.48 & -37.02 \\
\hline 1 & 1 & 4 & 12 & 1.40 & 1 & 1 & 4 & 7 & 4.89 & 4.80 \\
\hline 1 & 1 & 4 & 14 & -8.17 & 1 & 1 & 4 & 9 & -0.40 & -0.71 \\
\hline 1 & 1 & 4 & 16 & -20.48 & 1 & 1 & 4 & 14 & -23.41 & -22.75 \\
\hline 1 & 1 & 6 & 9 & 17.14 & 1 & 1 & 4 & 15 & -32.09 & -30.86 \\
\hline 1 & 1 & 6 & 12 & 7.86 & 2 & 2 & 8 & 26 & -30.95 & -30.58 \\
\hline 1 & 1 & 6 & 15 & -4.17 & 1 & 1 & 6 & 6 & 14.93 & 14.81 \\
\hline 1 & 1 & 6 & 18 & -18.82 & 1 & 1 & 6 & 18 & -31.28 & -32.03 \\
\hline 1 & 1 & 6 & 21 & -36.35 & 2 & 2 & 12 & 18 & 17.19 & 17.08 \\
\hline 1 & 1 & 6 & 22 & -43.66 & 2 & 2 & 12 & 20 & 11.02 & 11.03 \\
\hline \multirow[t]{6}{*}{1} & 1 & 6 & 23 & -51.66 & 2 & 2 & 12 & 24 & -1.53 & -1.60 \\
\hline & & & & & 2 & 2 & 12 & 28 & -16.80 & -16.96 \\
\hline & & & & & 2 & 2 & 12 & 30 & -25.66 & -25.64 \\
\hline & & & & & 2 & 2 & 12 & 33 & -40.64 & -41.86 \\
\hline & & & & & 2 & 2 & 12 & 34 & -46.63 & -47.44 \\
\hline & & & & & 2 & 2 & 12 & 35 & -53.29 & -54.90 \\
\hline
\end{tabular}


$\mathrm{pH}$ values from 2.5 to 9.5. As for 1:1:4 reagent ratio no hydroxycitrate formation was observed for 1:1:6.

\section{Titanium(IV) and disprosium (III) tartrates}

The results of the Dy(III)-Ti(IV)-d(dl)-Tart system's investigation by the method of $\mathrm{pH}$-metric titration and proton magnetic relaxation are presented in the Fig. 1c, 1d. The thermodynamic and relaxative characteristics of the heteronuclear tartrates are indicated in the table 1.

It is proposed that the equilibrium schemes of complex formation in the Dy(III)-Ti(IV) - d-Tart and Dy(III)-Ti(IV) - dl-Tart systems are similar. The calculation has indicated the identity of the complexes at equimolar ratios of metal : metal : ligand. Starting from $\mathrm{pH}=2$ at the reagent ratios of $\mathrm{B}_{\mathrm{Dy}(\mathrm{III})}: \mathrm{B}_{\mathrm{T}(\mathrm{IIII})}: \mathrm{C}_{\mathrm{dl}-\mathrm{H} 4 \mathrm{Tart}}=1: 1: 2$, the protonated cationic complexes $\left[\mathrm{DyTi}\left(\mathrm{H}_{3} \text { Tart }\right)_{2}\right]^{5+}$ and $\left[\mathrm{DyTi}\left(\mathrm{H}_{2} \text { Tart }\right)_{2}\right]^{3+}$ are present in the solution. The latter are dimerized at higher $\mathrm{pH}$ values (Eq. 7-8):

$$
2\left[\mathrm { DyTi } ( \mathrm { H } _ { 3 } \mathrm { Tart } _ { 2 } ] ^ { 5 + } \rightleftarrows 2 \left[\mathrm { Dy } \mathrm { Ti } ( \mathrm { H } _ { 2 } \mathrm { Tart } _ { 2 } ] ^ { 3 + } \rightleftarrows \left[\mathrm{Dy}_{2} \mathrm{Ti}_{2}\left(\mathrm{H}_{2} \text { Tart) }(\mathrm{HTart})_{3}\right]^{3+} \ldots\right.\right.\right.
$$

The $\mathrm{pH}$ range from 3 to 5 is characterized by the formation of the following dimers:

$\left[\mathrm{Dy}_{2} \mathrm{Ti}_{2}\left(\mathrm{H}_{2} \mathrm{Tart}(\mathrm{HT} \text { art })_{3}\right]^{3+} \rightleftarrows\left[\mathrm{Dy}_{2} \mathrm{~T}_{2}(\mathrm{H} \text { Tart) })_{2}(\text { Tart })_{2}\right]^{0} \rightleftarrows\left[\mathrm{Dy}_{2} \mathrm{Ti}_{2}(\mathrm{Tart})_{4}\right]^{2-} \rightleftarrows\left[\mathrm{Dy}_{2} \mathrm{Ti}_{2}(\mathrm{OH})(\mathrm{Tarr})_{4}\right]^{3-}\right.$

reagent ratios of $\mathrm{B}_{\mathrm{Dy}(\mathrm{IIII})}: \mathrm{B}_{\mathrm{Ti}(\mathrm{III})}: \mathrm{C}_{\mathrm{dl}-\mathrm{H} 4 \mathrm{Tart}}=1: 1: 2$, the protonated cationic complexes $\left[\mathrm{DyTi}\left(\mathrm{H}_{3} \text { Tart }\right)_{2}\right]^{5+}$ and $\left[\mathrm{DyTi}\left(\mathrm{H}_{2} \text { Tart }\right)_{2}\right]^{3+}$ are present in the solution. The latter are dimerized at higher $\mathrm{pH}$ values (Eq. 7-8):

$\left.2\left[\text { DyTi }\left(\mathrm{H}_{3} \text { Tart }\right)_{2}\right]^{5+} \rightleftarrows 2\left[\text { DyTi( } \mathrm{H}_{2} \text { Tart }\right)_{2}\right]^{3+} \rightleftarrows\left[\mathrm{Dy}_{2} \mathrm{Ti}_{2}\left(\mathrm{H}_{2} \text { Tart }\right)(\mathrm{HT} \text { art })_{3}\right]^{3+}$
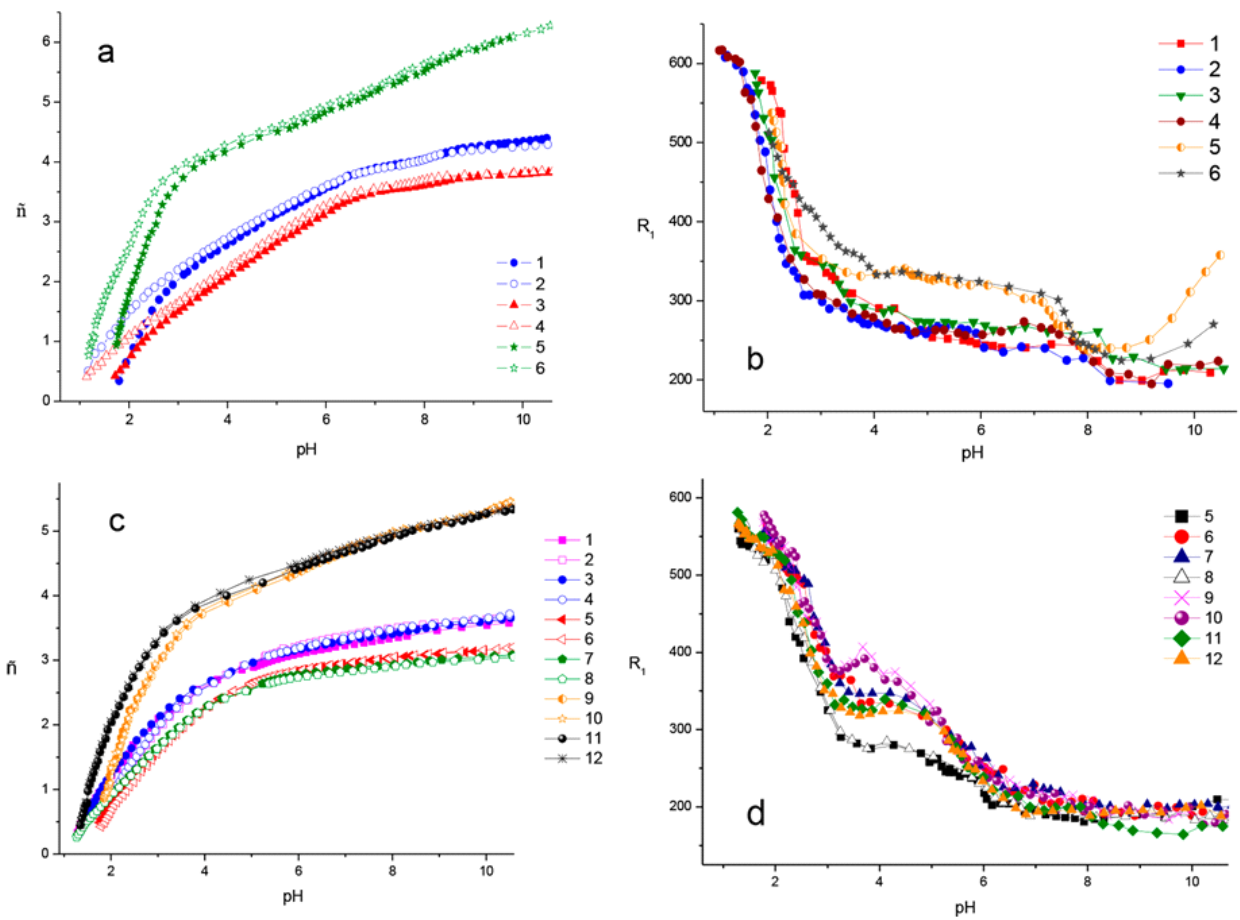

Fig. 1: Bjerrum plots and relaxivity for $\mathrm{Dy}(\mathrm{III}) \mathrm{Ti}(\mathrm{IV})-\alpha$-oxyacid systems for 1:1:2-1:1:6 metal-ligand ratios: $(\mathrm{a}, \mathrm{b}) 1-\mathrm{B}_{\mathrm{Dy}}=0.0026 \mathrm{M}, \mathrm{B}_{\mathrm{Ti}}=0.0026 \mathrm{M}, \mathrm{C}_{\mathrm{H} 4 \mathrm{Cit}}=0.0109 \mathrm{M} ; 2-\mathrm{B}_{\mathrm{Dy}}=0.01 \mathrm{M}, \mathrm{B}_{\mathrm{Ti}}=0.01 \mathrm{M}, \mathrm{C}_{\mathrm{H} 4 \mathrm{Cit}}=0.042 \mathrm{M} ; 3$ - $\mathrm{B}_{\mathrm{Dy}}=0.0026 \mathrm{M}, \mathrm{B}_{\mathrm{Ti}}=0.0026 \mathrm{M}, \mathrm{C}_{\mathrm{H} 4 \mathrm{Cit}}=0.0164 \mathrm{M} ; 4-\mathrm{B}_{\mathrm{Dy}}=0.01 \mathrm{M}, \mathrm{B}_{\mathrm{Ti}}=0.01 \mathrm{M}, \mathrm{C}_{\mathrm{H} 4 \mathrm{Cit}}=0.063 \mathrm{M} ; 5-\mathrm{B}_{\mathrm{Dy}}=0.0026$,

$\mathrm{B}_{\mathrm{Ti}}=0.0026 \mathrm{M}, \mathrm{C}_{\mathrm{H} 4 \mathrm{Cit}}=0.0055 \mathrm{M} ; 6-\mathrm{B}_{\mathrm{Dy}}=0.01 \mathrm{M}, \mathrm{B}_{\mathrm{Ti}}=0.01 \mathrm{M}, \mathrm{C}_{\mathrm{H} 4 \mathrm{Cit}}=0.0211 \mathrm{M} ; 7-\mathrm{B}_{\mathrm{Dy}(\mathrm{III})}=0.01 \mathrm{M}, \mathrm{C}_{\mathrm{H} 4 \mathrm{Cit}}=$ $0.0209 \mathrm{M} ; 8-\mathrm{B}_{\mathrm{Dy}}=0.01 \mathrm{M}, \mathrm{C}_{\mathrm{H} 4 \mathrm{Cit}}=0.0315 \mathrm{M}$. (c, d) 1, 2- $\mathrm{B}_{\mathrm{Dy}}=0.01 \mathrm{M} \mathrm{B}_{\mathrm{Ti}}=0.01 \mathrm{M}, \mathrm{C}_{\mathrm{d}(\mathrm{dl})-\mathrm{H} 4 \mathrm{tart}}=0.0412 \mathrm{M} ; 3,4$ $\mathrm{B}_{\mathrm{Dy}}=0.0026 \mathrm{M}, \mathrm{B}_{\mathrm{Ti}}=0.0026 \mathrm{M}, \mathrm{C}_{\mathrm{d}(\mathrm{dl}) \text {-H4tart }}=0.01 \mathrm{M} ; 5,6-_{\mathrm{Dy}}=0.0026 \mathrm{M}{ }_{\mathrm{Ti}}=0.0026 \mathrm{M}, \mathrm{C}_{\mathrm{d}(\mathrm{dl}) \text {-H4tart }}=0.0164 \mathrm{M} ; 7,8$ $-_{\mathrm{Dy}}=0.01 \mathrm{M}, \mathrm{B}_{\mathrm{Ti}}=0.01 \mathrm{M}, \mathrm{C}_{\mathrm{d}(\mathrm{dl}) \text {-H4tart }}=0.0631 \mathrm{M} ; 9,10-\mathrm{B}_{\mathrm{Dy}}=0.0026 \mathrm{M}, \mathrm{B}_{\mathrm{Ti}}=0.0026 \mathrm{M}, \mathrm{C}_{\mathrm{d}(\mathrm{d}) \text {-H4tart }}=0.0056 \mathrm{M}$; $11,12-B_{\mathrm{Dy}}=0.01 \mathrm{M}, \mathrm{B}_{\mathrm{Ti}}=0.01 \mathrm{M}, \mathrm{C}_{\mathrm{d}(\mathrm{dl}) \text {-H4tart }}=0.021 \mathrm{M}$ 
The $\mathrm{pH}$ range from 3 to 5 is characterized by the formation of the following dimers:

$\left[\mathrm{Dy}_{2} \mathrm{Ti}_{2}\left(\mathrm{H}_{2} \mathrm{Tart}\right)(\mathrm{HTart})_{3}\right]^{3+} \rightleftarrows\left[\mathrm{Dy}_{2} \mathrm{Ti}_{2}(\mathrm{H} \text { Tart })_{2}\left(\mathrm{Tarl}_{2}\right]^{0} \rightleftarrows\left[\mathrm{Dy}_{2} \mathrm{Ti}_{2}\left(\mathrm{Tarr}_{4}\right]^{2-} \rightleftarrows\left[\mathrm{Dy}_{2} \mathrm{Ti}_{2}\right.\right.\right.$ (OH)(Tart) $4^{3-}$

Already at $\mathrm{pH}>5$ the hydrolysis of dimeric complexes occurs. The formation of the 1:1:2 monomeric hydroxytartrates is increased. At subacidic, neutral and alkalescent medium $(\mathrm{pH} 5$ 8) the mono- and dinuclear complexes exist in the equilibrium (Eq. 9-10):

$$
\begin{gathered}
2\left[\text { DyTi }(\mathrm{OH})(\text { Tart })_{2}\right]^{2-} \rightleftarrows\left[\mathrm{Dy}_{2} \mathrm{Ti}_{2}(\mathrm{OH})_{2}(\text { Tart })_{4}\right]^{4-} \\
2\left[\text { DyTi }(\mathrm{OH})_{2}(\text { Tart })_{2}\right]^{3-} \rightleftarrows\left[\mathrm{Dy}_{2} \mathrm{Ti}_{2}(\mathrm{OH})_{4}(\text { Tart })_{4}\right]^{6-}
\end{gathered}
$$

At further increase in $\mathrm{pH}$ values $(\mathrm{pH} 8)$ an intensification of hydrolysis results in the destruction of the dimers. Mononuclear forms $\left[\mathrm{DyTi}(\mathrm{OH})_{3}\right.$ $\left.(\text { Tart })_{2}\right]^{4-}$ and $\left[\mathrm{DyTi}(\mathrm{OH})_{4}(\text { Tart })_{2}\right]^{5-}$ are formed in the strong-alkaline medium.

The complex formation at the excessive ligand concentration in the Dy(III)-Ti(IV)-d-Tart and Dy(III)-Ti(IV)-dl-Tart systems results in generation of forms with similar stoichiometry. At the reagent ratios of 1:1:4 for $d$ - and dl-isomers of the tartaric acid an insignificant difference in relaxation curves was observed (at $\mathrm{pH} 2.5-5$ ). As observed from modeling of the complexes' equilibrium composition, the difference occurs due to a higher $\mathrm{R}_{1}$ values for dl-tartaric acid $\left[\mathrm{DyTi}\left(\mathrm{H}_{3} \text { Tart }\right)\left(\mathrm{H}_{2} \text { Tart }\right)_{3}\right]^{0}$ $(1: 1: 4: 7)$. $R_{1}$ values for this complex exceed the respective parameter of the form with d-ligand by $14 \%$. The graduated character of the relaxation curves at 2 or 3 -fold excess in the ligand concentration allows to make a number of propositions regarding the complexes formed. In particular, in the stong-acidic medium the relaxivity $\mathrm{R}_{1}$ of the aquo ion $\left[\mathrm{Dy}\left(\mathrm{H}_{2} \mathrm{O}\right)_{8}\right]^{3+}$ is $600 \mathrm{~mol}^{-1} \mathrm{~s}^{-1} \mathrm{~L}$. However, a decrease in relaxivity in the acidic medium $(\mathrm{pH}=1.3-2)$ indicates a binding of dysprosium (III) ion into a complex. The fact may be related to the formation of mononuclear complex particles $\left[\mathrm{DyTi}\left(\mathrm{H}_{3} \text { Tart }\right)\left(\mathrm{H}_{2} \text { Tart }\right)_{3}\right]^{0}\left(\mathrm{R}_{1}=538.0 \mathrm{~mol}^{-1} \mathrm{~s}^{-}\right.$ $\left.{ }^{1} \mathrm{~L}\right)$ and $\left[\mathrm{DyTi}\left(\mathrm{H}_{3} \text { Tart }\right)_{6}\right]^{+}$. The respective $\mathrm{R}_{1}$ values for complexes based on d- and dl-tartrates are 534.6 and $539.2 \mathrm{~mol}^{-1} \mathrm{~s}^{-1} \mathrm{~L}$.

After the decrease in relaxation efficiency $(\mathrm{pH} 2-3)$ the curves reach a plateau $(\mathrm{pH} 3-4.5)$. At the same time, $\mathrm{B}_{\mathrm{Dy}(\mathrm{III})}=0.0026 \mathrm{~mol} / \mathrm{L}$ at molar reagent ratio 1:1:6 an increase in relaxivity is also observed. In the acidic medium $(\mathrm{pH}=2-3)$ the ions $\left[\text { DyTi }\left(\mathrm{H}_{2} \text { Tart }\right)_{3}(\mathrm{HTart})\right]^{2-}\left(\mathrm{R}_{1}=353.6\right.$ and $360.1 \mathrm{~mol}^{-1} \mathrm{~s}$ ${ }^{1} \mathrm{~L}$ for complexes with dl- and d-tartaric acids, respectively), $\left[\mathrm{Dy}_{2} \mathrm{Ti}_{2}\left(\mathrm{H}_{3} \text { Tart }\right)_{6}\left(\mathrm{H}_{2} \text { Tart }\right)_{6}\right]^{4-}\left(\mathrm{R}_{1}=405.3\right.$ and $407.8 \mathrm{~mol}^{-1} \mathrm{~s}^{-1} \mathrm{~L}$, respectively), and $\left[\mathrm{Dy}_{2} \mathrm{Ti}_{2}\left(\mathrm{H}_{3} \text { Tart }\right)_{4}\left(\mathrm{H}_{2} \text { Tart }\right)_{8}\right]^{6-}\left(\mathrm{R}_{1}=344.0\right.$ and $310.7 \mathrm{~mol}^{-}$ ${ }^{1} \mathrm{~S}^{-1} \mathrm{~L}$, respectively) are present in the system.

A plateau at $\mathrm{pH}=3-4.5$ is characterized by the forms $\left[\mathrm{Dy}_{2} \mathrm{Ti}_{2}\left(\mathrm{H}_{2} \text { Tart }\right)_{12}\right]^{10-}\left(\mathrm{R}_{1}=386.8\right.$ and 344.9 $\left.\mathrm{mol}^{-1} \mathrm{~S}^{-1} \mathrm{~L}\right),\left[\mathrm{Dy}_{2} \mathrm{Ti}_{2}\left(\mathrm{H}_{2} \text { Tart }\right)_{8}(\mathrm{HTart})_{4}\right]^{14-}\left(\mathrm{R}_{1}=365.68\right.$ $\left.367.3 \mathrm{~mol}^{-1} \mathrm{~s}^{-1} \mathrm{~L}\right)$ and $\left[\mathrm{Dy}_{2} \mathrm{Ti}_{2}\left(\mathrm{H}_{2} \text { Tart }\right)_{6}(\text { HTart })_{6}\right]^{16-}$ $\left(\mathrm{R}_{1}=352.8\right.$ and $\left.330.8 \mathrm{~mol}^{-1} \mathrm{~s}^{-1} \mathrm{~L}\right)$. At higher $\mathrm{pH}$ values $(\mathrm{pH}=4.5-6.5)$ a decrease in relaxivity is observed again (the forms $\left[\mathrm{Dy}_{2} \mathrm{Ti}_{2}\left(\mathrm{H}_{2} \mathrm{Tart}\right)_{3}(\mathrm{HTart})_{9}\right]^{19-}$, $\mathrm{R}_{1}=307.9$ and $296.5 \mathrm{~mol}^{-1} \mathrm{~s}^{-1} \mathrm{~L}$; [Dy ${ }_{2} \mathrm{Ti}_{2}$ (HTart) (Tart) $\left.{ }_{2}\right]^{12-}, R_{1}=284.8$ and $\left.292.1 \mathrm{~mol}^{-1} \mathrm{~s}^{-1} \mathrm{~L}\right)$.

Further increase in the $\mathrm{pH}(6.5-10.5)$ does not affect the relaxivity values. Dimeric heteronuclear dysprosium (III) and titanium (IV) tartrates $\left(\left[\mathrm{Dy}_{2} \mathrm{Ti}_{2}\left(\mathrm{H}_{2} \text { Tart }\right)_{2}(\mathrm{HTart})_{10}\right]^{20-}\left(\mathrm{R}_{1}=224.3\right.\right.$ and $180.4 \mathrm{~mol}^{-1} \mathrm{~s}^{-1} \mathrm{~L}$, respectively) are converted into mononuclear species [DyTi(HTart $\left.)_{2}(\text { Tart })_{2}\right]^{7-}$ $\left(\mathrm{R}_{1}=211.2\right.$ and $\left.220.8 \mathrm{~mol}^{-1} \mathrm{~s}^{-1} \mathrm{~L}\right)$, [DyTi(HTart $\left.)_{6}\right]^{11-}$ $\left(\mathrm{R}_{1}=192.8\right.$ and $\left.176.5 \mathrm{~mol}^{-1} \mathrm{~s}^{-1} \mathrm{~L}\right)$, [DyTi(HTart)(Tart) $\left.{ }_{3}\right]^{8-}$ $\left(R_{1}=195.6\right.$ and $\left.189.0 \mathrm{~mol}^{-1} \mathrm{~s}^{-1} \mathrm{~L}\right)$ in the alkaline medium $(\mathrm{pH}>7.5)$.

The aqueous speciation models were determined for the Dy(III)-Ti(IV)"citrate and d(dl)tartrate system. It is important to note, that these heteronuclear complexes are formed all over the

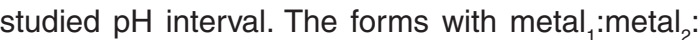
ligand ratio of $1: 1: 2,1: 1: 4$, and $1: 1: 6$ are observed for complexes both with citric and tartaric acid. The complex with 1:1:3 reagents ratio was detected only in citric solutions. The observed fact may be a consequence of specific geometric structure of citric acid. Moreover, steric difficulties of such form's formation are absent. The ability of citric acid to form these 1:1:3 complexes was demonstrated earlier by Todorovsky et al. in the $\mathrm{Ln}(\mathrm{III})-\mathrm{Ti}(\mathrm{IV})-\mathrm{H}_{4}$ Cit and $\mathrm{Ce}(\mathrm{IV})-\mathrm{Ti}(\mathrm{IV})-\mathrm{H}_{4}$ Cit systems (13). The author has also indicated that $\alpha$-hydroxo-, $\alpha$-carboxy- and $\beta$ carboxyl groups take part in the coordination of the central atom with the ligand. In the presence of citric acid $\mathrm{Ti}(\mathrm{IV})$ and Dy(III) formed only mononuclear 
species, while in the tartaric acid solution both the monomers and dimers exist in equilibrium. The tendency of tartaric acid to form binuclear specie with $\mathrm{Ti}(\mathrm{IV})$ is noted also by the authors $(15,16)$. The study of dysprosium(III) and titanium(IV) speciation in aqueous solutions of $\mathrm{d}(\mathrm{dl})$-tartaric acid in the acidic range $(\mathrm{pH} 2-4.5)$ is accompanied the precipitates formation in a widely concentrations range of Dy(III) $\left(B_{\text {Dy(III) }}=0.0026-0.01 M\right)$. The precipitation occurs almost immediately after preparation of the solutions when the ratio metal. metal $_{2}$ : ligand amount to $1: 1: 2$. The need to use a large excess of $\mathrm{d}(\mathrm{dl})$-tartaric acid is explained by the fact that the study of the chemistry heteronuclear tartrate complexes' formation was carried out only at large reactants ratios. Unlike the system Dy(III) citric acid, where the precipitates were formed in the $\mathrm{pH}$ range $2.5-4.5\left(\mathrm{~B}_{\mathrm{Dy}}=0.01 \mathrm{~mol} / \mathrm{L}\right)$ in the investigated heteronuclear systems Ti(IV)- Dy(III) $\mathrm{H}_{4}$ Cit precipitation was not observed throughout the studied $\mathrm{pH}$ range.

\section{ACKNOWLEDGEMENTS}

We are grateful to Prof. Yu. I. Sal'nikov for CPESS program placed at our disposal.

\section{REFERENCES}

1. Buettner, K.; Valentine. A. Chem. Rev. 2012 112, 1863-1881.

2. Deng, Y.-F.; Jiang, Y.-Q.; Hong, Q.-M.; Zhou, Z.-H. Polyhedron. 2007, 26, 1561-1569.

3. Panagiotidis, P.; Kefalas, E.T.; Raptopoulou, C.P.; Terzis, A.; Mavromoustakos, T.; Salifoglou A. Inorg. Chim. Acta. 2008, 361, 2210-2224.

4. Kefalas, E.; Panagiotidis, P.; Raptopoulou, C.; Terzic, A.; Mavromoustakos, T.; Salifoglou A. Inorg. Chem. 2005, 44, 2596-2605.

5. Dakanali, M.; Kefalas, E.T.; Raptopoulou, C.P.; Terzis, A.; Voyiatzis, G.; Kyrikou, I.; Mavromoustakos, T.; Salifoglou A. Inorg. Chem. 2003, 42, 4632-4639.

6. Kemmitt, T.; Al-Salim, N.I.; Gainsford, G.J.; Bubendorfer, A.; Waterland M. Inorg. Chem. 2004, 43, 6300-6306.

7. Zumreoglu-Karan., B. Coord. Chem. Rev. 2006, 250, 2295-2307.

8. Deng, Y.-F.; Zhou, Z.-H.; Wan, H.-L. Inorg. Chem. 2004, 43, 6266-6273.
9. Macyka, W.; Szacilowski, K.; Stochel, G.; Buchalskaa, M.; Kuncewicza, J.; Labuza. P. Coord. Chem. Rev. 2010. 254, .2687-2701

10. Kakihana, M.; Tada, M.; Shiro, M.; Petrykin, V.; Osada, M.; Nakamura. Y. Inorg. Chem. 2001, 40, 891-894.

11. Uppal, R.; Incarvito, C.; Lakshmi, K.; Valentine. A. Inorg. Chem. 2006, 45, 1795-1804.

12. Krishan, B., Prakash, O.J., El-Mossalamy, Orient J. Chem., 2013, 29(1), 381-388.

13. Todorovsky, D.S.; Getsova, M.M.; Milanova, M.M.; Kakihana, M.; Petrova, N.L.; Arnaudov, M.G.; Enchev, V.G. Can. J. Chem. 2007, 85, 547-559.

14. Silanova, M.M.; Arnaudov, M.G.; Getsova, M.M.; Todorovsky D.S. J. Alloy Compd. 1998, 264, 95-103.

15. Shi, H.; Yu, C.; He, J. J. Catal, 2010, 271, 7987.

16. Shi, H.; Yu, C.; He, J. J. Phys. Chem. C. 2010, 114, 17819-17828. 